\title{
Avaliação da eficácia da fita teste utilizada para determinar a concentração do ácido peracético
}

\author{
Natália Peres Gonçalves Pavani*, Ana Lúcia Colombo, M.Sc.**, Setsuko Sato, M.Sc.***
}

\begin{abstract}
*Enfermeira, graduada pela Universidade Sagrado Coração (USC) Bauru SP, ${ }^{* *}$ Docente das disciplinas Ética, Bioética e Enfermagem Perioperatória e Centro de Material no curso de Graduação em Enfermagem da Universidade Sagrado Coração (USC), Enfermeira da Central de Materiais e Esterilização do Hospital Unimed Bauru, ***Docente das disciplinas FísicoQuímica, Química Orgânica, Química Geral e Ensino de Química da Universidade Sagrado Coração (USC), Especialista em Especialização em Metodologia do Ensino Superior, Especialista em Especialização de Professores do Ensino Superior
\end{abstract}

\section{Resumo}

O ácido peracético é um desinfetante de alto nível e esterilizante para artigos termossensíveis. Mas o processo de esterilização e desinfecção com o ácido peracético é um método de difícil monitoração quanto a sua efetividade. O estudo desenvolvido foi do tipo descritivo de caráter quantitativo, tendo como objetivo avaliar a eficácia dos métodos de monitoração dos processos de desinfecção e esterilização com ácido peracético, avaliando, assim, o aspecto fidedigno dos resultados obtidos com os testes, garantindo a confiança do profissional enfermeiro sobre os processos e sua tranqüilidade em relação à segurança de seus pacientes. Foram utilizados 2 tipos de amostras do ácido peracético, coletadas em 3 períodos de tempo diferentes. Após a coleta foram realizados 2 tipos de testes: com a fita teste (recomendado pelo fabricante do ácido) e o teste laboratorial para quantificação da concentração de ácido peracético presente na amostra (iodometria). Em seguida, os resultados dos testes foram comparados. Concluiu-se que os resultados obtidos com os testes laboratoriais são mais fidedignos, pois se aproximam da concentração de ácido peracético indicada pelo fabricante da solução. Além disso, concluiu-se, também, que a solução mantém uma concentração satisfatória de ácido peracético por um período de tempo maior que trinta dias.

Palavras-chave: ácido peracético, teste, esterilização, desinfecção.

\section{Abstract \\ Evaluation of effectiveness of the test trip used to determine peracetic acid concentration}

The peracetic acid is a high-level disinfectant and sterilant for thermosensible materials. But the process of sterilization and disinfection with peracetic acid is difficult for monitoring its effectiveness. This study with a descriptive quantitative approach aims at evaluating the effectiveness of monitoring procedures for disinfection and sterilization with peracetic acid, in order to assess reliable tests results, ensuring nursing professional confidence on processes and tranquility in relation to patient's safety. 2 types of samples of peracetic acid were used, which were collected on 3 different periods of time. After collection 2 types of 
tests were performed: the test strip (recommended by the acid manufacturer) and laboratory test to quantify peracetic acid concentration in the sample (iodometry). Then, the test results were compared. It was concluded that the results of laboratory tests are more reliable because the peracetic acid concentration is quite the same solution specified by the manufacturer. Additionally, the solution maintains a satisfactory concentration of peracetic acid for a period longer than thirty days.

Key-words: peracetic acid, test, sterilization, disinfection.

\section{Resumen \\ Evaluación de la eficacia de la cinta de prueba utilizada para determinar la concentración de ácido peracético}

El ácido peracético es un desinfectante de alto nivel y esterilización para materiales termosensibles. Pero el proceso de esterilización y desinfección con ácido peracético es un método de difícil seguimiento en cuanto a su eficacia. Estudio descriptivo de naturaleza cuantitativa que tiene como objetivo evaluar la eficacia de los procedimientos de control para la desinfección y esterilización con ácido peracético, evaluando, así, los resultados fiables de las pruebas, garantizando la confianza de los profesionales de enfermería en los procesos y la tranquilidad en la seguridad de sus pacientes. Se utilizaron 2 tipos de muestras de ácido peracético, recogida en 3 diferentes períodos de tiempo. Después de recogida 2 tipos de pruebas fueron realizadas: la prueba de cinta (recomendado por el fabricante del ácido) y las pruebas de laboratorio para cuantificar la concentración de ácido peracético en la muestra (yodometría). Los resultados de la prueba se compararon después. Con esto, podemos concluir que los resultados de las pruebas de laboratorio son más fiables, porque son más próximos a los de la concentración de ácido peracético especificado por el fabricante de la solución. También se concluyó que la solución satisfactoria mantiene una concentración de ácido peracético por un período superior a treinta días.

Palabras-clave: ácido peracético, test, esterilización, desinfección.

\section{Introdução}

A escolha dos métodos de processamento dos materiais cirúrgicos envolve a resistência dos artigos ao processo e os tipos de microorganismos encontrados.

Atualmente, devido à revolução tecnológica, deparamo-nos com um aumento de cirurgias mínimamente invasivas. A maioria dos instrumentais utilizados para estes tipos de cirurgias é sensível ao calor e à umidade, portanto, não pode ser autoclavado. Uma das alternativas é a desinfecção de alto nível ou esterilização química por ácido peracético.

O ácido peracético é um desinfetante de alto nível para artigos termossensíveis, que tem ação esterilizante para alguns artigos e materiais termossensíveis, por exemplo, os cateteres e os materiais de videocirurgia [1]. Também é utilizado na indústria de alimentos como sanificante de superfícies [2]. Souza [3] cita também seu uso para desinfecção de águas de abastecimento e esgotos sanitários. Possui ação sobre todas as formas de vida de microorganismos sendo bactericida, esporicida, fungicida e virucida [4]. É composto por uma mistura equilibrada de ácido acético, peróxido de hidrogênio e água. $\mathrm{O}$ mecanismo de ação acontece ao oxidar enzimas es- senciais para as reaçóes bioquímicas de sobrevivência e de reprodução dos microorganismos [5].

Legalmente, o princípio ativo ácido peracético foi incluído na Portaria no 15 , de 23/08/88, que determina o registro de produtos saneantes domissanitários com finalidade antimicrobiana, através da Portaria no 122/DNT, de 29 de Novembro de 1993, que autoriza a utilização do mesmo em nosso país como esterilizante, desinfetante hospitalar para superfícies fixas, desinfetante hospitalar para artigos semi-críticos e desinfetante para indústria alimentícia [6].

O processo de esterilização e desinfecção com o ácido peracético é um método de difícil monitoração quanto à sua efetividade [5]. Partindo deste princípio, pretende-se com este estudo avaliar a eficácia dos métodos de monitoração dos processos de desinfecção e esterilização com ácido peracético, avaliando, assim, o aspecto fidedigno dos resultados obtidos com os testes, garantindo a confiança do profissional enfermeiro sobre os processos e sua tranqüilidade em relação à segurança de seus pacientes.

Durante estágio extracurricular, realizando a limpeza e desinfecção com ácido peracético de alguns materiais semi-críticos, questionou-se a eficácia 
do método utilizado para medir a concentração do ácido peracético. Após tal questionamento, iniciouse uma busca das respostas através de referenciais teóricos. Devido à escassez de conteúdo teórico brasileiro, nasceu a idéia de realizar uma revisão bibliográfica e um estudo laboratorial sobre o ácido peracético e os possíveis métodos para validação do processo de desinfecção e esterilização.

A presente pesquisa contou com a ajuda de graduandos e profissionais de enfermagem e da área de exatas (químicos), para ser realizada.

\section{Materiais e métodos}

\section{Solução à base de ácido peracético}

Esterilizante químico à base de ácido peracético Sterilife ${ }^{\odot}$ - Lifemed, fabricado por Peróxidos do Brasil Ltda. Apresentação individual em embalagem de 5 litros com uma unidade de sachê inibidor de corrosão presa em sua alça, este deve ser adicionado na embalagem contendo a soluçáo, antes do uso [7].

\section{Fita indicadora para teste de concentraçáo e re- síduo do ácido peracético:}

Embalagem contendo 100 tiras de ensaio, Merckoquant ${ }^{\oplus}$ - Merck. As fitas reagem por método colorimétrico com a presença de ácido peracético, produzindo cores que são graduadas em valores que variam de 5 a $50 \mathrm{mg} / \mathrm{l}$ de ácido peracético [8].

\section{Casuística}

Foram coletados dois tipos de amostras da solução de ácido peracético em uso: uma amostra contendo $99 \mathrm{ml}$ de água destilada $+1 \mathrm{ml}$ de ácido peracético (recomendaçóes do fabricante da fita para realizaçáo do teste com a fita indicadora) e outra amostra com $100 \mathrm{ml}$ puro da mesma solução. As coletas foram realizadas em três períodos: 15 dias de uso, 30 dias e 40 dias posteriormente.

As amostras passaram por análise no Laboratório de Química para avaliação da concentração do ácido puro. Os resultados obtidos foram comparados com os resultados da fita teste.

Os métodos utilizados para quantificação das amostras foram:

1. Determinação da concentração de peróxido de hidrogênio e ácido peracético em soluçóes de desinfecção por permanganimetria e iodometria, que consiste na dissolução da amostra em solução de ácido sulfúrico diluído e resfriado a uma temperatura próxima de $0^{\circ} \mathrm{C}$. O peróxido de hidrogênio da amostra é titulado com uma solução padronizada de permanganato de potássio até coloração rósea permanente. Logo após é adicionada uma solução de iodeto de potássio, e o iodo liberado é titulado com solução padronizada de tiossulfato de sódio, usando-se amido como indicador. Tal determinaçáo foi utilizada seguindo as recomendaçóes da Solvay - Peróxidos do Brasil LTDA [9].

2. Análise da concentração de ácido peracético por meio da fita teste de concentraçáo e resíduo da Merck (Merckoquant). De acordo com as recomendaçôes do fabricante da fita, a técnica consiste em diluir $1 \mathrm{ml}$ da soluçáo de ácido peracético em $99 \mathrm{ml}$ de água destilada, em seguida introduzir a zona de reaçáo da fita por aproximadamente um segundo na amostra utilizada para medição, logo após, retirar a fita da solução e deixar o excesso de líquido escorrer por aproximadamente cinco segundos. A partir disso classifica-se a cor da zona de reação da fita teste.

\section{Análise dos resultados}

Os resultados foram analisados através $\mathrm{da}$ comparação dos valores obtidos com a fita teste da Merck com os valores alcançados com os testes recomendados pela Peróxidos do Brasil, que indica as seguintes equaçóes para se chegar aos resultados:

$\mathrm{Na}$ análise por permanganimetria e iodometria a concentraçáo de peróxido de hidrogênio $\left(\mathrm{H}_{2} \mathrm{O}_{2}\right)$ presente na amostra, expressa em ppm, é dada pela seguinte expressão:

$$
\mathrm{CH}_{2} \mathrm{O}_{2}=\frac{\mathrm{A} \times \mathrm{fl} \times \mathrm{N1} \times 17.008}{\mathrm{~V}}
$$

A concentração de ácido peracético $(\mathrm{CH} 3 \mathrm{COOOH})$ presente na amostra, expressa por ppm, é dada pela seguinte expressão:

$$
\text { Cperacético }=\frac{(B-C) \times f 2 \times 3.800}{V}
$$

Onde: $\mathrm{V}=$ Volume da amostra em $\mathrm{ml} ; \mathrm{A}=$ Volume da solução de permanganato de potássio $\left(\mathrm{KMnO}_{4}\right)$ gasto na titulação de $\mathrm{H}_{2} \mathrm{O}_{2} \mathrm{em} \mathrm{ml,} \mathrm{B}=$ Volume da solução de 
tiossulfato de sódio $\left(\mathrm{Na}_{2} \mathrm{~S}_{2} \mathrm{O}_{3}\right)$ gasto na titulação do iodo liberado em ml; $\mathrm{C}=$ Volume da soluçáo de tiossulfato de sódio $\left(\mathrm{Na}_{2} \mathrm{~S}_{2} \mathrm{O}_{3}\right)$ gasto na titulação da prova em branco em $\mathrm{ml}$; N1 = Normalidade da solução de permanganato de potássio $(\mathrm{KMnO} 4)$; f1 = Fator da solução de permanganato de potássio $\left(\mathrm{KMnO}_{4}\right)$ utilizada na titulaçáo do $\mathrm{H}_{2} \mathrm{O}_{2} ; \mathrm{f} 2=$ Fator da solução de tiossulfato de sódio $\left(\mathrm{Na}_{2} \mathrm{~S}_{2} \mathrm{O}_{3}\right)$ utilizada na titulação do iodo liberado.

A determinação do resultado através da fita teste da Merck é feita de acordo com o parâmetro de uma escala de cores (Figura 1) fornecida pelo fabricante da fita, onde a escala de 0 a 50 expressa o valor da concentração de ácido peracético em mg/l.

Figura 1 - Parâmetro para determinação de ácido peracético.

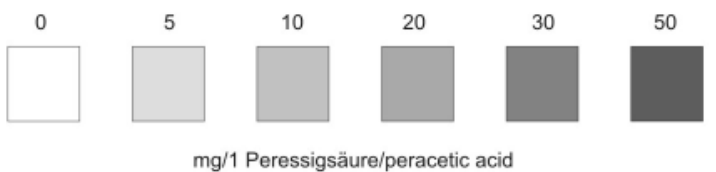

Fonte: Merck

\section{Métodos estatísticos}

Para a comparaçáo estatística entre os grupos foi realizado o teste ANOVA pareado.

\section{Resultados e discussão}

A casuística foi composta por dois tipos de amostras coletadas em três períodos de tempo diferentes, como já mencionado.

A primeira amostragem foi colhida após 15 dias de uso da solução. Os resultados foram os seguintes:

Fita teste: após a realização do teste conforme instruções do fabricante da fita, a coloração indicada marcou uma concentração de $50 \mathrm{mg} / \mathrm{l}$ de ácido peracético. Então, se em um litro da solução encontra-se $50 \mathrm{mg}$ de ácido peracético, em cinco litros (conteúdo total do frasco da soluçáo utilizada) teremos $250 \mathrm{mg}$ de ácido peracético.

Teste laboratorial: em $10 \mathrm{ml}$ da solução pura utilizada, foram encontradas $2,852 \mathrm{ppm}$ de ácido peracético, então em um litro teremos $285 \mathrm{ppm}$ ou $\mathrm{mg} / \mathrm{l}$ pois ppm [partes por milhão é o mesmo que $\mathrm{mg} / \mathrm{l}$ (miligramas por litro)], portanto em cinco litros teremos $1.425 \mathrm{mg}$ de ácido peracético.

A segunda amostra foi coletada após 30 dias de uso da solução, onde obtivemos os resultados:

Fita teste: a coloração indicou a concentração de $30 \mathrm{mg} / \mathrm{l}$, em cinco litros totalizará $150 \mathrm{mg}$ de ácido peracético.

Teste laboratorial: encontramos 2,459 ppm em $10 \mathrm{ml}$ da soluçáo pura utilizada, em um litro isso totaliza $246 \mathrm{ppm}$ e em cinco litros $1.230 \mathrm{mg}$ de ácido peracético.

A terceira e última amostra foi coletada após 40 dias de uso da solução e os resultados foram:

- Fita teste: a coloração manteve-se igual à segunda amostra, ou seja, $30 \mathrm{mg} / \mathrm{l}$.

- Teste laboratorial: em $10 \mathrm{ml}$ da solução pura utilizada foram encontradas 2,210 ppm, isso significa que em um litro da solução encontram-se $221 \mathrm{ppm}$ e em cinco litros $1.105 \mathrm{mg}$ de ácido peracético.

Comparando-se os resultados da fita teste com os testes laboratoriais temos uma diferença significativa entre os valores. A média desta diferença de variação é de $1.070 \mathrm{mg}$ de ácido peracético a mais para o teste laboratorial.

No manual do usuário Sterilife, diz apenas que a solução é a base de ácido peracético a 0,2\%, não indicando, portanto, a concentração em ppm.

Kunigk [10] cita em sua tese que $0,5 \%$ de ácido peracético é o mesmo que $5.000 \mathrm{mg} / \mathrm{l}$. 0,35\% de ácido peracético é igual a $3.500 \mathrm{ppm}$. Então uma solução a $0,2 \%$ significa $2.000 \mathrm{ppm}$ ou $\mathrm{mg} / \mathrm{l}$ de ácido peracético.

Sendo assim, a análise que se aproxima deste valor é a análise laboratorial, portanto, a concentração encontrada na fita não é a concentração real.

A análise estatística dos resultados é apresentada e comentada nas tabelas abaixo.

$\mathrm{Na}$ Tabela I encontra-se a comparação estatística entre os grupos pelo teste ANOVA pareado, em que se verifica uma probabilidade de 0,0352 que é menor que 0,05 apresentando diferença significante entre os grupos.

Tabela I - Comparação estatística pelo teste Anova.

\begin{tabular}{llllll}
\hline Fonte de variação & Soma de quadrados & Grau de liberdade & Quadrado médio & "F" & Probabilidade \\
\hline Grupos & 1717350.00 & 1 & 1717350.00 & 282.1108 & 0.00352 \\
Réplicas & 46508.3333 & 2 & 23254.1666 & & \\
Interação & 12174.9999 & 2 & 6087.49999 & & \\
\hline Total & 1776033.33 & 5 & & & \\
\hline
\end{tabular}


Tabela II - Média e desvio padrão da concentração do ácido peracético nos grupos estudados.

\begin{tabular}{llll}
\hline Grupo & Média & Desvio padrão & Número \\
\hline Fita teste & 183.3333 & 57.7350269 & 3 \\
Teste laboratorial & 1253.333 & 161.270993 & 3 \\
\hline
\end{tabular}

A Tabela II apresenta a média e desvio padrão da concentração do ácido peracético encontrado nos dois grupos.

As análises estatísticas contribuíram para confirmar o resultado alcançado, ou seja, a diferença da concentração de ácido peracético para os dois tipos de teste foram significativas.

\section{Conclusão}

Pudemos observar que os resultados das concentraçóes de ácido peracético obtidos com a fita teste e com os testes laboratoriais são diferentes. Os resultados alcançados com os testes laboratoriais são mais fidedignos, pois se aproximam da concentração de ácido peracético indicada pelo fabricante da solução.

Uma sugestão seria a utilização de fitas indicadoras sensíveis para intervalos de graduação maiores dos que estão sendo utilizados $(5-50 \mathrm{mg} / \mathrm{l})$, pois com os testes laboratoriais obtivemos em todas as amostras concentraçóes maiores que 200 ppm, então as fitas teste utilizadas não foram capazes de identificar tais valores. Existem no mercado, assim como observado na bula do teste de ácido peracético da Merck, fitas com intervalo de medida de 100-500 $\mathrm{mg} / \mathrm{l}$ de ácido peracético, talvez esse seria o teste recomendado para o tipo de soluçáo utilizada.

Outra conclusão é que a solução mantém uma concentração satisfatória de ácido peracético por um período de tempo maior que trinta dias. Porém, acreditamos que o período recomendado pelo fabricante da soluçáo, serve como margem de segurança para que os usuários do produto não ultrapassem mais que 40 dias de uso da solução.

\section{Agradecimentos}

À USC por ceder o laboratório de química para realização dos testes. À Clínica de Fisioterapia da USC por ajudar-nos com as amostras do ácido peracético e pela doação das fitas teste utilizadas.

\section{Referências}

1. Lacerda RA. Controle de infecção em centro cirúrgico: fatos, mitos e controvérsias. São Paulo: Atheneu; 2003.

2. Moraes MSV, Andrade NJ, Chaves JBP, Passos FJV, Gomide LAM. Isolamento de esporos em equipamentos de abatedouros avícolas e avaliação de sua resistência a sanificantes químicos. Ciênc Tecnol Aliment 1997;17(3).

3. Souza JB, Daniel LA. Comparação entre hipoclorito de sódio e ácido peracético na inativação de E. coli, colifagos e C. perfingens em água com elevada concentração de matéria orgânica. Eng Sanit Ambient 2005;10(2).

4. Possari JF. Centro de material e esterilização: planejamento e gestão. 2a ed. São Paulo: Iátria; 2005.

5. SOBECC. Práticas recomendadas: centro-cirúrgico, recuperação pós-anestésica, centro de material e esterilização. 4a ed. São Paulo: Congraf; 2007.

6. Ministério da Saúde. Portaria 122/DTN de 29 de novembro de 1993. Inclui o princípio ácido peracético para uso das formulaçóes de desinfetantes/esterilizantes. Secretaria de Vigilância Sanitária, Brasília, D.F., 29 dezembro 1993. Brasília: MS; 1993.

7. Sterilife. Ácido peracético à $0,2 \%$ - manual do usuário. [s.l.]: Lifemed, [s.d.].

8. MERCK. Merckoquant Test Ácido Peracético (bula do produto). Alemanha. (venda somente para estabelecimentos de saúde). Lote: hc748156.

9. SOLVAY Peróxidos do Brasil Ltda. Análise de ácido peracético - soluções de desinfecção [online]. [citado 2007 Set 21]. Disponível em URL:http://www. peroxidos.com.br/library/bysection/result/0,0,_PT1000054,00.html

10. Kunigk L. Ação do ácido peracético sobre microorganismos contaminantes do processo cervejeiro [tese]. São Paulo: Universidade de São Paulo; 1998. 